\title{
PA2.26 antigen (T1 $\alpha /$ podoplanin): a small mucin-like transmembrane glycoprotein associated with cell migration and cancer
}

\author{
Ester Martín Villara ${ }^{a}$ Francisco Gómez Scholl ${ }^{\mathrm{a}, \mathrm{c}}$, Carlos Gamallo Amat ${ }^{\mathrm{b}}$ and Miguel Quintanilla Ávila ${ }^{\mathrm{a}}$ \\ anstituto de Investigaciones Biomédicas Alberto Sols. CSIC-UAM. Madrid. Spain.

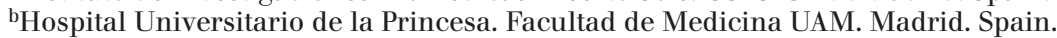 \\ ${ }^{c}$ Columbia University. Department of Physiology and Cellular Biophysics. Center for Neurobiology and Behavior. New York. USA.
}

PA2.26 antigen was originally identified as a small mucin-type glycoprotein induced during chemical carcinogenesis on mouse skin. Cloning and sequencing of the murine and human PA2.26 cDNAs revealed that the sequence was identical to other reported proteins termed T1 $\alpha$ (a marker for alveolar type I epithelial cells) and podoplanin (a glycoprotein expressed in glomerular podocytes). In this review, we summarise the current knowledge on the biology of PA2.26 (T1 $\alpha /$ podoplanin). Although the physiological function of this protein is not well established as yet, several characteristics make this molecule unique among mucin-like glycoproteins. For example, PA2.26 (T1 $\alpha /$ podoplanin) appears to play an important role in morphogenesis during development, and it is a marker for the lymphatic endothelium. In cancer, PA2.26 is induced in tumours derived from squamous epithelia, and is associated with cell migration and malignant progression. These findings are discussed in the context of cancer-associated membrane mucins in which PA2.26 antigen, together with a newly-discovered small mucin called dysadherin, form a special group.

Key words: PA2.26, T1 $\alpha$, podoplanin, mucin, cell migration, metastasis, lymphatic endothelium,

Martín Villar E, Gómez Scholl F, Gamallo Amat C, Quintani-

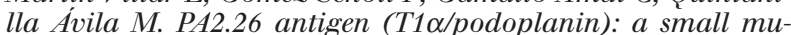
cin-like transmembrane glycoprotein associated with cell migration and cancer. Rev Oncol 2003;5(9):491-9

\section{Antígeno PA2.26 (T1 $\alpha /$ podoplanina): una glucoproteína transmembrana tipo mucina de pequeño tamaño asociada con la migración celular y el cáncer}

El antígeno PA2.26 fue identificado originalmente como una glucoproteína tipo mucina de pequeño tamaño cuya expresión se induce durante la carcinogénesis química de piel de ratón. El clonaje y la secuenciación de los cADNs murino y humano reveló que PA2.26 era idéntica a otras proteínas conocidas, denominadas como $\mathrm{T} 1 \alpha$ (un marcador para células epiteliales tipo I de los alvéolos) y podoplanina (una glucoproteína presente en los podocitos de los glomérulos). En esta revisión resumimos lo que se sabe actualmente sobre la biología de PA2.26 (T1 $\alpha /$ podoplanina). Aunque la función fisiológica de esta proteína no se conoce todavía en profundidad, ciertas características de esta molécula la hacen única entre las glucoproteínas tipo mucina. Así, PA2.26 (T1 $\alpha /$ podoplanina) parece desempeñar un papel importante en la morfogénesis durante el desarrollo embrionario, y es un marcador del endotelio linfático. En el cáncer, PA2.26 se induce en tumores derivados de epitelios escamosos, asociada con la migración celular y la progresión maligna. Estos hallazgos se discuten en el contexto de las mucinas transmembrana relacionadas con el cáncer, de las cuales el antígeno PA2.26 junto con desadherina, otra mucina de pequeño tamaño descubierta recientemente, forman un grupo especial.

Palabras clave: PA2.26, T1 $\alpha$, podoplanina, mucina, migración celular, metástasis, endotelio linfático.
Correspondence: Dr. M. Quintanilla.

Instituto de Investigaciones Biomédicas Alberto Sols (IIB).

CSIC - UAM.

C/ Arturo Duperier, 4.

28029 Madrid. Spain.

E-mail:mquintanilla@iib.uam.es

Received 22 September 2003; Accepted 7 October 2003.

\section{INTRODUCTION}

Mucins are very large glycoproteins $(>200 \mathrm{kDa})$ that contain 50\%-80\% carbohydrates by weight, predominantly O-linked sugars to the abundant Ser and Thr residues present in their backbones. They are the major constituents of viscous mucus in the tracheobronchial, gastrointestinal and reproductive tracts, for- 
ming highly disulfide cross-linked gels that serve as lubricants and protection of the underlying epithelia ${ }^{1}$. A second class of mucins, the membrane-associated mucins, differ greatly in structure and function from the secreted mucins. The typical membrane-associated mucins contain a hydrophobic membrane-spanning domain and a large extracellular domain consisting of repetitive mucin sequences and many Pro residues, that results in an extended and rigid structure that may reach a length of several hundred nanometers $^{1,2}$. Epithelial transmembrane mucins have received increasing attention, first because their enhanced expression in carcinomas and adhesive modulating properties ${ }^{2}$, and second for their involvement in cellular signaling ${ }^{3}$. Although about a dozen of membrane mucin genes have been cloned from different species, the best characterized are MUC1 (episialin) and MUC4 (sialomucin).

MUC1 is present in simple secretory epithelial tissues, and the elevated levels of expression found in carcinomas and metastatic lesions suggest that it has a role in tumor progression and metastasis ${ }^{1}$. It is thought to be an anti-adhesive molecule due to its large, extended, extracellular domain that reduces cellcell and cell-substratum adhesion by steric hyndran$\mathrm{ce}^{4,5}$, but MUC1 on pancreas and colon carcinoma cells has adhesive features because it presents carbohydrate structures that might be ligands for selectins on endothelial cells, enabling metastatic dissemination of cancer cells ${ }^{6,7}$. On the other hand, several observations suggest that MUC1 might play a role in cellular signaling since it bind members of the ErbB family of tyrosine kinase receptors ${ }^{3}$. MUC1 also interacts with $\beta$-catenin ${ }^{8}$, a component of cell-cell adherens junctions and a regulator of transcription that acts as an oncoprotein in colorectal cancer ${ }^{9}$. A more clear indication of a cell signaling function for mucins has come from studies with MUC4, a heterodimeric glycoprotein complex with anti-adhesive properties originally identified in highly metastatic rat mammary adenocarcinoma cells ${ }^{10}$. The transmembrane subunit of MUC4 (ASPG-2) is the only ligand to date characterized for ErbB2. MUC4 binding to ErbB2 induces Tyr phosphorylation of the receptor and enhances expression of the cyclin-dependent kinase inhibitor p $27^{\mathrm{kip}}$, an effect that is reversed by neuregu$\operatorname{lin}^{11}$, a ligand for ErbB3 for which ErbB2 is considered a co-receptor.

Other membrane mucins present in blood endothelial cells and leukocytes function as ligands for the selectin family of carbohidrate-binding proteins. These mucins are involved in cell-cell interactions and mediate leukocyte migration from the blood stream into tissue, thrombosis and inflammation ${ }^{12,13}$. Prototypic mucins from this group are CD34 $\left(M_{r} 90 \mathrm{kDa}\right)$, a ligand for L-selectin which is expressed in endothelial cells and in pluripotent stem cell of the bone marrow, and CD43 (sialophorin, leukosialin, $\mathrm{M}_{\mathrm{r}}$ 100-150 kDa), expressed in leukocytes and platelets, which is defective in patients with the X-linked Wiskott-Aldrich syndrome, a profound immunodefficiency in T-cell function.

In this article, we will review the properties of PA2.26 antigen, a small membrane-associated mucin originally identified as a cell-surface glycoprotein induced in basal epidermal keratinocytes and dermal fibroblast-like cells during mouse skin carcinogenesis and wound healing ${ }^{14,15}$.

\section{PA2.26 ANTIGEN: A NOVEL CELL-SURFACE MUCIN-TYPE GLYCOPROTEIN}

\section{Structure of PA2.26 antigen}

PA2.26 protein was identified by a monoclonal antibody produced against mouse epidermal keratinocytes transformed by the chemical carcinogen dimethylbenzanthracene (DMBA) ${ }^{14}$. Cloning and sequencing of the murine $P A 2.26 \mathrm{cDNA}^{15}$ revealed a backbone of 172 amino acids containing an N-terminal signal peptide sequence and a highly hydrophobic membrane spanning domain. The extracellular domain contained only a putative N-glycosylation site while potential O-glycosylation Ser and Thr residues were very abundant. In fact, the biochemical characterization of immunopurified PA2.26 revealed that it is a highly glycosylated mucin-type protein containing sialic acid linked $\alpha(2-3)$ to galactose $\beta(1-3) \mathrm{N}$-acetylgalactosami$\mathrm{ne}^{15}$ (fig. $\left.1 \mathrm{~A}, \mathrm{~B}\right)$. The extremely short cytoplasmic domain composed of only 9 amino acids has not obvious functional motifs except a Ser (Ser 167) which is a potential phosphorylation site for cAMP-dependent protein kinase (PKA) and protein kinase C (PKC) and a cluster of basic aminoacids reported to be a binding site for proteins of the ezrin, radixin, moesin (ERM) family ${ }^{16}$. ERM proteins play structural and regulatory roles in the formation of cell-surface extensions by linking transmembrane proteins to the actin cytoskeleton $^{17}$, and the interaction of PA2.26 with proteins of this family could be a key event for the biological action exerted by PA2.26 in the cells (see below). We have recently cloned the full human PA2.26 cDNA (Martín-Villar et al, submitted) and found that its amino acid sequence is highly conserved respect to the mouse protein, particularly in the transmembrane and cytoplasmic domains. Interestingly, the human endodomain conserves the putative ERM binding site as well as the potential phosphorylation site for PKA and PKC, suggesting that these two motifs are functionally important (fig. 1A). The human and mouse PA2.26 genes are located in chromosomes 1 and 4, respectively. They encode polypeptides that migrate at $21 \mathrm{kDa}$ (human) and $27 \mathrm{kDa}$ (mouse) in SDS-polyacrylamide gels, while the mature glycosylated 
A

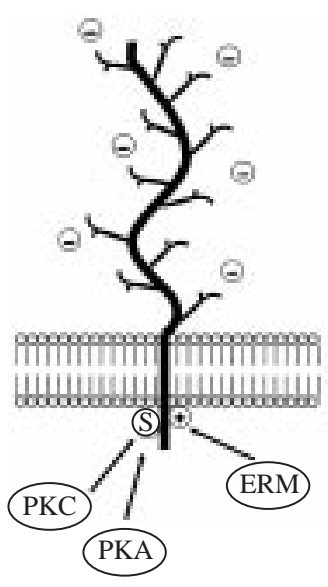

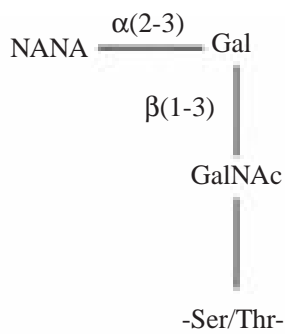

MUC4 (Sialomucin)

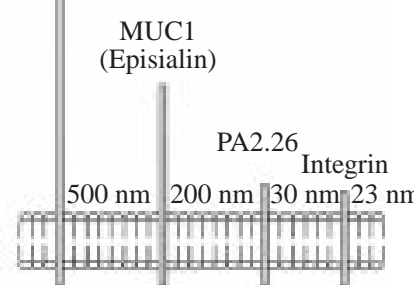

Fig. 1. Structure of PA2.26 antigen. A) Schematic representation of the PA2.26 backbone showing the highly O-glycosylated ectodomain as well as the positively charged location for binding of ERM proteins and potentially phosphorylated Ser in the endodomain. B) O-glycan chains linked to Ser or Thr in the PA2.26 ectodomain. NANA: N-acetylneuraminic acid (sialic acid); Gal: galactose; GalNAc: N-acetylgalactosamine. C) Comparison of the lengths of ectodomains among several transmembrane glycoproteins (in a mucin-like domain 20-amino acids residues are approximately 5-nm long). forms raise sizes of about 40 and $45 \mathrm{kDa}$, respectively. PA2.26 antigen is, therefore, the smallest transmembrane mucin known to date. In contrast to large MUC1 and MUC4 mucins whose ectodomains may extend at least 200-500 $\mathrm{nm}$ above the cell membrane ${ }^{2}$, the length of the PA2.26 ectodomain is about $30 \mathrm{~nm}$, in the range of cell adhesion receptors as integrins and cadherins (fig. 1C). Recently, a new membrane glycoprotein of small size, dysadherin, has been cloned from human cells ${ }^{18}$. Dysadherin is a cancer-associated mucin of 178 amino acids whose sequence is unrelated to PA2.26 but share with PA2.26 structural and functional similarities (see below).

\section{PA2.26-related proteins: many collars for the same cat?}

Two cDNAs encoding proteins with amino acid sequences almost identical to that of PA2.26 were first described in the mouse: OTS- 8 as a phorbol ester-induced gene in cultured osteoblast cells ${ }^{19}$; and gp 38 encoding a marker of type I epithelial cells in the thymus and of stromal cells in T-dependent cell areas of peripheral lymphoid tissues ${ }^{20}$. Other PA2.26-related proteins have been described in different species (summarized in table 1). Thus, several glycoproteins which share high identity sequences were identified in the rat: E11 as a marker for cells of the osteoblastic lineage ${ }^{21}, \mathrm{~T} 1 \alpha$ and RTI40 expressed by alveolar type I cells in the lung $\mathrm{g}^{22,23}$, and podoplanin as a marker of glomerular epithelial cells (podocytes) ${ }^{24}$. In addition, gp40, a canine homologous of PA2.26, has been reported to act as a main receptor for the influenza $\mathrm{C}$ virus in Madin-Darby canine kidney (MDCK) cells ${ }^{25}$. The human homologues for several of these proteins have also been described: gp36 as the corresponding dog gp $40^{26}$, and $\mathrm{T} 1 \alpha-1$ and $\mathrm{T} 1 \alpha-2$ as the human isoforms of rat $\mathrm{T} 1 \alpha^{27}$.
The present evidence suggests that all these proteins are encoded by the same gene. Thus, the cDNA sequences reported for human $g p 36^{26}, T 1 \alpha-2^{27}$ and $p o$ doplanin (GenBank accession number AF390106) are identical to that of human PA2.26 (GenBank accession number AY194238; Martín-Villar et al, submitted), while the nucleotide sequence reported for the another human isoform of rat T1 $\alpha, T 1 \alpha-1^{27}$ (GenBank accession number AF030427) seems to be an experimental artifact as it does not correspond to a cDNA but to a sequence comprising exon 5 and part of the flanking introns of the PA2.26 gene. Therefore, PA2.26, T1 $\alpha$ and podoplanin are identical proteins. Nevertheless, although likely all of the above mentioned PA2.26-related proteins (table 1) are encoded by a single, highly conserved gene, some heterogeneity of protein products might exist that could account for discrepancies in the pattern of tissue distribution reported for some of these proteins. This heterogeneity could be generated either by post-translational modifications (allowing to differences in the recognition by antibodies) or alternative splicing. In regard with the latter, no mechanistic explanation has been reported for the expression of two distinct PA2.26/podoplanin transcripts of 2.7 and $0.9-\mathrm{kb}$ in human tissues ${ }^{28}$ (Martín-Villar et al, submitted).

\section{EXPRESSION STUDIES}

PA2.26 (T1 $\alpha /$ podoplanin) is developmentally regulated and expressed in a wide variety of cell types in adult tissues

PA2.26 antigen exhibits a broad cellular distribution in adult mouse normal tissues. It is expressed in all types of mesothelia as well as in epithelial cells of alveoli, ependyma, choroid plexuses and glomeruli, concentrated on the apical side of the cells and asso- 
TABLE 1. Summary of PA2.26-related proteins

\begin{tabular}{|c|c|c|c|}
\hline Species & Name & Identified as & References \\
\hline \multirow[b]{3}{*}{ Mouse } & OTS-8 & Phorbol ester-inducible gene in cultured osteoblasts & 19 \\
\hline & gp38 & Marker of stromal cells in T-cell-dependent areas of peripheral lymphoid tissues & 20 \\
\hline & $\begin{array}{l}\text { Podoplanin } \\
\text { (gp38P) }\end{array}$ & $\begin{array}{l}\text { Protein that controls the shape of podocytes and is down-regulated } \\
\text { in experimental nephrosis }\end{array}$ & 53 \\
\hline \multirow{5}{*}{ Rat } & $\mathrm{T} 1 \alpha$ & Marker of alveolar type I epithelial cells of the lung & 22 \\
\hline & RT140 & & 23 \\
\hline & E11 & Marker for the late steps in the differentiation pathway of the osteoblastic lineage & 21 \\
\hline & Podoplanin & $\begin{array}{l}\text { Protein that controls the shape of podocytes and is down-regulated in } \\
\text { experimental nephrosis }\end{array}$ & 24 \\
\hline & OTS-8 & Antigen expressed on rat tumor vascular endothelial cells & 54 \\
\hline \multirow[t]{2}{*}{ Dog } & gp40 & Main receptor for influenza C virus & 25 \\
\hline & $\mathrm{T} 1 \alpha$ & Marker of alveolar type I epithelial cells of the lung & 27 \\
\hline \multirow[t]{2}{*}{ Human } & gp36 & $\begin{array}{l}\text { Sialoglycoprotein expressed at the apical plasma membrane of the vascular } \\
\text { endothelium and alveolar epithelium }\end{array}$ & 26 \\
\hline & Podoplanin & Lymphatic endothelial marker & 30 \\
\hline
\end{tabular}

ciated with microvilli ${ }^{15}$. This pattern of expression coincides with that found for $\mathrm{T} 1 \alpha$ and podoplanin 24,29 . In human tissues, PA2.26 antigen has also been found to be present in osteocytes, regenerating skeletal muscle cells and fibroblast-like cells with a dendritic morphology (Martín-Villar et al, submitted). But the most remarkable finding raised in these studies is that PA2.26/podoplanin is specifically expressed in the lymphatic endothelium, but not in endothelia of blood vessels in both rodent and human tissues ${ }^{15,30}$ (Martín-Villar et al, submitted).

Several reports have described that expression of $\mathrm{T} 1 \alpha$ is developmentally regulated. During mouse embryonic development it is detected in the foregut endoderm at day E8.5-9.0. Its expression pattern changes during lung morphogenesis from wide-spread in the embryonic lung epithelium to restricted expression to type I cells of the distal epithelium ${ }^{22,29,31}$. The gene is also expressed in the developing nervous system. High levels of expression are found in the early neural tube but, by midgestation the gene is down-regulated being detected only in the choroid plexus in adult brain ${ }^{15,21,29}$.

In addition, PA2.26/T1 $\alpha /$ podoplanin is expressed in lymphatic progenitor cells at around E11.0 $0^{32}$. These endothelial cells are located on one side of the anterior cardinal vein and express Prox-1, a homeobox transcription factor ${ }^{33,34}$. Prox-1 appears to be a master control gene that determines lymphatic endothelial cell fate by repressing expression of blood vascular endothelial cell-specific genes and inducing lympha-

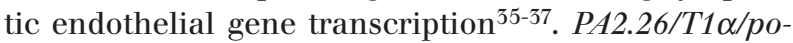
doplanin is one of the primary Prox-1-induced genes $^{37}$. In contrast to Prox-1-null mice, which fail to develop any lymphatic vasculature ${ }^{36}, P A 2.26 / T 1 \alpha / p o-$ doplanin knock-out mice can develop a peripheral lymphatic vascular system, but exhibit pronounced defects in lymphatic vascular organization and function $^{32}$ (see below).

\section{The importance of being a specific marker for the lymphatic endothelium}

The lymphatic vascular system plays an important physiological role in the control of tissue fluid homeostasis and in the immune response. Lymphatic capillaries drain the fluid and proteins exudated into the tissues and direct antigen-presenting cells to the lymph nodes. Dysfunction or abnormal development of lymphatic vessels results in lymphedema, which is characterized by fluid accumulation (edema), impaired immunity and fibrosis ${ }^{38}$. The lymphatic vascular system is also involved in the metastatic spread of malignant tumors. Clinical and pathological observations suggest that transport of tumor cells via lymphatics is the most common pathway of initial dissemination to the regional lymph nodes for many carcinomas $^{38-40}$. In fact, the detection of lymph node metastases in cancer patients is significant for both tumor staging and the design of treatment protocols. However, despite these well established principles questions concerning to the mechanisms of tumor spread via lymphatics still remain unanswered; i. e., it is not known whether tumor cells disseminate through preexisting vessels or whether they require lymphatic capillaries formed de novo by lymphangiogenesis $^{40,41}$. In the studies on cancer, the lymphatic vascular system has been traditionally overshadowed by the greater emphasis placed on the blood vascular system (angiogenesis). This has been due, in part, by the difficulties in recognizing lymphatic vessels in tissues by only morphological criteria because of the 
absence of lymphatic specific markers ${ }^{42}$. Although a number of lymphatic specific markers have been recently reported, such as the transcription factor Prox-1, the vascular endothelial growth factor receptor VEGFR-3/flt-4 and the hyaluronan receptor LYVE-1, among others, many of them are also expressed in blood vessels in certain physiological and pathological situations or are only present in lymphatic vessels of certain tissues (see reference 40 for a review). In contrast, PA2.26/podoplanin appears to be a reliable marker for lymphatic capillaries (it is not expressed in the large lymphatic collectors ducts) in all normal and pathological situations studied to date. Consequently, specific antibodies recognizing PA2.26/podoplanin are now being widely used to study the lymphatic microvasculature in human cancer ${ }^{43,44}$.

\section{PA2.26 ANTIGEN AND CANCER}

\section{PA2.26 is induced in squamous cell carcinomas}

PA2.26 antigen was first identified in the experimental model of mouse skin carcinogenesis ${ }^{14}$. PA2.26 is absent from the normal epidermis as well as from cultured nontumorigenic keratinocytes but it is present in skin carcinoma cell lines. In vivo, it is induced at a high frequency in basal-like cells of mouse skin papillomas and carcinomas generated by treatment with DMBA and TPA. In addition, the antigen is abundantly synthesized by stromal cells of the tumors and cultured fibroblasts ${ }^{14}$. Studies on human cancer indicate that PA2.26 is not expressed in breast, colorectal, gastric and lung adenocarcinomas and melanomas. Nevertheless, PA2.26 is induced in a subset of early oral squamous cell carcinomas (Martín-Villar et al, submitted). Taken together, these observations suggest that PA2.26 could be a marker for tumors derived from squamous stratified epithelia.

This is in contrast to dysadherin, another small cancer-associated membrane mucin which is expressed in a wide variety of carcinomas including those derived from the pancreas, breast, colon, lung, stomach and bladder ${ }^{18,45,46}$. Dysadherin is also expressed in normal lymphocytes, blood vascular endothelial cells and, interestingly, in basal cells of normal stratified squamous epithelia ${ }^{18}$. Although PA2.26 is absent from the normal stratified epithelia, it is induced in basal epidermal keratinocytes during wound healing and after treatment of the skin with TPA ${ }^{14}$. PA2.26 is also expressed in the hyperplastic epithelium adjacent to oral squamous carcinomas (Martín-Villar et al, submitted) always restricted to the basal proliferative layer, and no expression has been found in differentiating suprabasal keratinocytes. These results indicate that PA2.26 might be involved in reactive processes during tissue remodeling and carcinogenesis. Wound healing and tumor development are dynamic proces- ses that implicate the interaction of several tissue types. These interactions are potentiated by reciprocal signaling between the epithelium and stromal fibroblasts and involve paracrine diffusible growth factors that stimulates infiltration of macrophages, promotes angiogenesis, reduces epithelial adhesiveness and increases epithelial cell proliferation and migration ${ }^{47}$. PA2.26 expression during wound healing and carcinogenesis could be induced by growth factors or cytokines that stimulate proliferation and/or locomotion of basal keratinocytes.

\section{PA2.26 promotes cell migration and metastasis}

The first evidence for a relationship between PA2.26 antigen and cell migration came from confocal immunofluorescence and electron microscopy studies aimed to determine the subcellular localization of the antigen in carcinoma and fibroblast cell lines. PA2.26 was concentrated in actin-rich microvilli and plasma membrane extensions, such as filopodia, lamellipodia and ruffles, where it colocalized with members of the ERM protein family and actin filaments ${ }^{15}$ (fig. 2). ERM proteins appear to regulate many fundamental cellular processes involving the plasma membrane and underlying actin cytoskeleton, such as cell shape, cell migration, membrane trafficking and membrane transport. Furthermore, there is evidence supporting a role for ERM proteins in signal transduction. ERM proteins bind the Rho GDP dissociation inhibitor (RhoGDI), a sequestering and negative regulator of Rho GTPase, allowing activation of the Rho pathway $^{48}$. ERM proteins have been reported to anchorage several cell adhesion molecules as CD44, ICAM-2 and CD43 directly to actin filaments. For other proteins, such as the PDGF receptor and the cystic fibrosis transmembrane conductance regulator CFTR, linking to F-actin is indirect and requires binding of ERM to scaffolding proteins ${ }^{17}$. Immunoprecipitation of PA2.26 from cell lysates coprecipitated ezrin and moesin, but not radixin ${ }^{15}$. Furthermore, pull-down experiments with the intact and mutant PA2.26 endodomains coupled to Sepharose suggest that PA2.26 binds ezrin directly through the juxtamembrane cluster of positively charged amino acids present in its endodomain (Scholl and Quintanilla, unpublished results). The fact that radixin does not appear to bind PA2.26 is in agreement with the relative distribution found for ERM proteins and PA2.26 in vivo. While the tissue distribution of PA2.26 coincides with that of ezrin or moesin in polarized cells of mesothelia, choroid plexuses, alveoli and glomeruli ${ }^{15,49}$, concentrated in microvilli or cell-surface protrusions, radixin is primarily expressed in cells that do not express PA2.26, such as hepatocytes and bile canaliculi ${ }^{50}$. Transfection of PA2.26 cDNA into immortalized premalignant keratinocytes promoted plasma membrane 

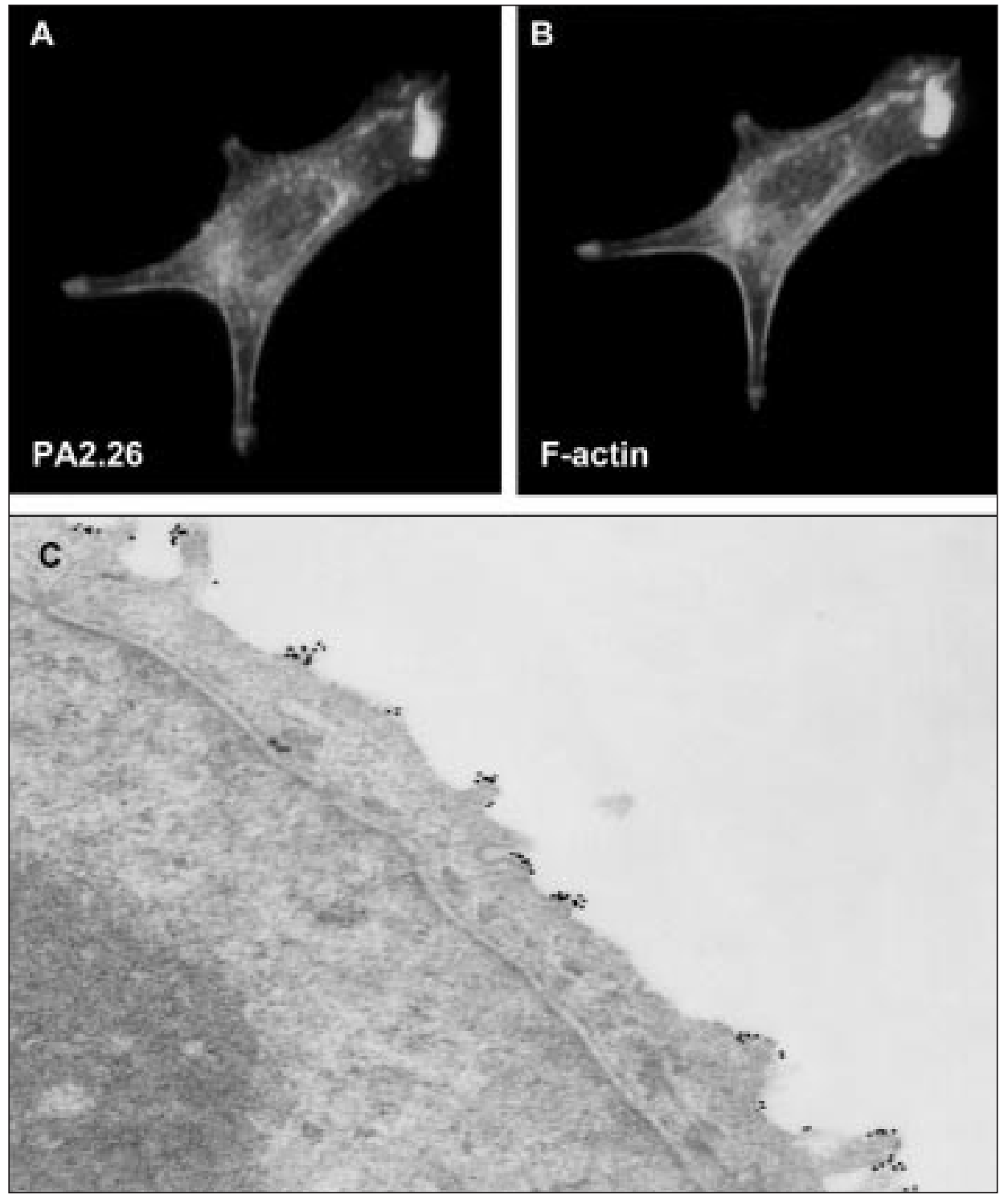

Fig. 2. PA2.26 is concentrated at plasma membrane projections. A and B) Confocal immunofluorescence colocalization of PA2.26 with actin filaments (F-actin) at cell-surface extensions in carcinoma cells. C) Immunoelectron microscopic localization of PA2.26 at membrane microvilli in carcinoma cells. extensions and cell migration ${ }^{15}$. PA2.26 induced a redistribution of ezrin from short microvilli to longer filopodia, lamellipodia and ruffles allowing to a reorganization of the actin cytoskeleton in which cortical actin bundles and stress fibers were lost. Importantly, E-cadherin was anomalously localized out of cell-cell contacts and proteolitically degraded leading to destabilization of cell-cell junctions and enhanced invasiveness and metastasis ${ }^{51}$. Upon injection in nude mice, PA2.26 transfectants produced highly undifferentiated carcinomas that metastasized into regional lymph nodes, while parental cells and control transfectants gave rise as much to small cysts of benign appearance ${ }^{51}$. The induction of elongated cell extensions and cytoskeletal reorganization, together with the enhanced migration of stably PA2.26-transfected keratinocytes, are in agreement with the effects on the motility of endothelial cells observed after transfection of T1 $\alpha /$ podoplanin ${ }^{32}$. These results suggest an important role for PA2.26 on the induction and stabilization of cellular protrusions at the leading edge of migrating cells. In cancer cells, the effects of PA2.26 on the plasma membrane and cytoskeleton could suppress E-cadherin function allowing to enhanced invasiveness and metastasis. Similar effects on cell-cell adhesion and E-cadherin expression have been observed for dysadherin. Dysadherin tends to be expressed in tumor regions where cell-cell contacts are loose, and transfection of dysadherin into liver cancer cells resulted in down-regulation of E-cadherin protein expression and enhanced metastasis ${ }^{18}$. Dysadherin has been found to interact with actin filaments ${ }^{18}$, although its association with ERM proteins remains as an open question. 
Overally, small cancer-associated membrane mucins appear to play a key role in malignant progression. They can inactivate E-cadherin function without affecting its expression at the mRNA level by a novel mechanism that involves a reorganization of the actin cytoskeleton. We have postulated that this mechanism implicates the interaction of the cytoplasmic domain of PA2.26 with ezrin ${ }^{51}$. However, a contribution of the glycoprotein ectodomain can not be ruled out at present.

\section{TOWARDS A BIOLOGICAL FUNCTION FOR PA2.26 (T1 $\alpha /$ PODOPLANIN)}

The presence of PA2.26 in relatively fixed cells in normal tissues suggest another function besides its postulated role in cell migration and malignant progression. In this regard, the generation of $T 1 \alpha$ null mice containing a targeted mutation in the $T 1 \alpha$ gene locus has revealed important insights about the function of PA2.26/T1 $\alpha /$ podoplanin in normal cells and tissues. While mice with heterozygous disruption of the $T 1 \alpha$ gene were healthy and fertile, $T 1 \alpha$ null mice died immediately after birth, due to respiratory failure caused by impaired formation of alveolar airspace and reduced numbers of differentiated type I alveolar epithelial cells in the lung ${ }^{31}$. Although the function of $T 1 \alpha$ in the alveolar epithelium is unknown, the lung phenotype of $T 1 \alpha$ null mice appears to be related to a general dysregulation of proliferation in the distal lung at the expense of correct type I cell differentiation, possibly by disruption of epithelial-mesenchymal signaling ${ }^{31}$. The $T 1 \alpha$ null mice also showed defects in the lymphatic, but not blood vessel pattern formation. These defects were associated with congenital lymphedema, dilation of lymphatic vessels and diminished lymphatic transport and have been attributed to impaired cell to substratum adhesion and migration ${ }^{32}$. These results suggest an important role for this glycoprotein in the development of the lung and lymphatic vascular system, but additional studies are required to unravel the precise function of PA2.26/T1 $\alpha /$ podoplanin in the alveolar epithelium and lymphatic endothelial cells.

The localization of PA2.26/T1 $\alpha /$ podoplanin at the apical cell surface of mesothelial, epithelial and endothelial cells, at membrane regions exposed to an internal or external fluid compartment, together with its negatively charged structure typical of mucins are compatible with a protective function from environmental agents and proteases ${ }^{1,2}$. On the other hand, a role for this glycoprotein in fluid transport has also been proposed, although studies aimed to demonstrate this hypothesis have failed ${ }^{27}$.

PA2.26 could also act as a ligand for lectins, as do selectin-binding mucins present in blood endothelial cells and leukocytes ${ }^{12}$. In this regard, it is of interest to emphasize that carbohydrate modifications in the ectodomain of PA2.26 (sialic acid linked $\alpha(2-3)$ to galactose $\beta(1-3) \mathrm{N}$-acetylgalactosamine) (fig. 1) is an optimal location for recognition by lectins that bind sialic acid, also denominated Siglecs (Sialic acid-binding immunoglobulin superfamily lectins) ${ }^{52}$. However, nothing is known about the possible interactions of PA2.26 with other extracellular proteins or matrix components.

In summary, PA2.26 antigen appears to fullfil several functions during late development, tissue repair and carcinogenesis. While its involvement in cell motility has been clearly demonstrated in keratinocytes and endothelial cells ${ }^{15,32,51}$, further work is necessary to analyze its possible role in other cellular processes such as cell adhesion and signal transduction. To this end, the knowledge of interactions of PA2.26 with other membrane proteins or extracellular components will be of paramount interest in the future.

\section{ACKNOWLEDGEMENTS}

The work on PA2.26 antigen carried out by our laboratory has been supported by grants from the "Fondo de Investigación Sanitaria" (FIS), "Ministerio de Ciencia y Tecnología" (MCyT) and "Comunidad Autónoma de Madrid" (CAM) of Spain. EM-V is supported by a fellowship from the FIS.

\section{References}

1. Gendler SJ, Spicer AP. Epithelial mucin genes. Annu Rev Physiol 1995;57:607-34.

2. Hilkens J, Ligtenberg MJL, Vos HL, et al. Cell membrane-associated mucins and their adhesion-modulating properties. Trends Biochem Sci 1992;17:359-63.

3. Carraway KL, Ramsauer VP, Haq B, et al. Cell signaling through membrane mucins. BioEssays 2002;25:66-71.

4. Wesseling J, van der Valk SW, Vos HL, et al. Episialin (MUC1) overexpression inhibits integrin-mediated cell adhesion to extracellular matrix components. J Cell Biol 1995;129:255-65.

5. Wesseling J, van der Valk SW, Hilkens J. A mechanism for inhibition of E-cadherin-mediated cell-cell adhesion by the membrane associated mucin episialin/MUC1. Mol Biol Cell 1996;7:565-77.

6. Zhang K, Baeckstrom D, Brevinge H, et al. Comparison of sialyl-Lewis a-carrying CD43 and MUC1 mucin secreted from a colon carcinoma cell line for E-selectin binding and inhibition of leukocyte adhesion. Tumor Biol 1997;18:175-87.

7. Zhang K, Baeckstrom D, Brevinge H, et al. Secreted MUC1 mucins lacking their cytoplasmic part and carrying sialyl-Lewis a and $\mathrm{x}$ epitopes from a tumor cell line and sera of colon carcinoma patients can inhibit HL-60 leukocyte to E-selectin-expressing endothelial cells. J Cell Biochem 1996;60:538-49.

8. Yamamoto M, Bharti A, Ly I, et al. Interaction of the DF3/MUC1 breast carcinoma-associated antigen and $\beta$ catenin in cell adhesion. J Biol Chem 1997;272:12492-4.

9. Ben-Ze'ev A, Shtutman M, Zhurinsky J. The integration of cell adhesion with gene expression: The role of $\beta$-catenin. Exp Cell Res 2000;261:75-82. 
10. Komatsu M, Carraway CAC, Fregien NL, et al. Reversible disruption of cell-matrix and cell-cell interaction by overexpression of sialomucin complex. $\mathrm{J}$ Biol Chem 1997;272:33245-54.

11. Jepson S, Komatsu M, Haq B, et al. Muc4/sialomucin complex, the intramembrane ErbB2 ligan, induces specific phosphorylation of ErbB2 and enhances expression of p27 (kip), but does not activate mitogen-activated kinase or protein kinaseB/Akt pathways. Oncogene 2002; 21:7524-32.

12. Varki A. Selectin ligands. Proc Natl Acad Sci USA 1994; 91:7390-7.

13. Shimizu Y, Shaw S. Mucins in the mainstream. Nature 1993;366:630-1.

14. Gandarillas A, Scholl FG, Benito N, et al. Induction of PA2.26, a cell-surface antigen expressed by active fibroblasts, in mouse epidermal keratinocytes during carcinogenesis. Mol Carcinog 1997;20:10-8.

15. Scholl FG, Gamallo C, Vilaró S, et al. Identification of PA2.26 antigen as a novel cell-surface mucin-type glycoprotein that induces plasma membrane extensions and increased motility in keratinocytes. J Cell Sci 1999;112: 4601-13.

16. Yonemura S, Hirao M, Doi Y, et al. Ezrin/radixin/moesin (ERM) proteins bind to a positively charged amino acid cluster in the juxta-membrane cytoplasmic domain of CD44, CD43, and ICAM-2. J Cell Biol 1998;140:885-95.

17. Bretscher A, Edwards K, Fehon RG. ERM proteins and merlin: integrators at the cell cortex. Nat Rev Mol Cell Biol 2002;3:586-99.

18. Ino Y, Gotoh M, Sakamoto M, et al. Dysadherin, a cancer-associated cell membrane glycoprotein, down-regulates E-cadherin and promotes metastasis. Proc Natl Acad Sci USA 2002;99:365-70.

19. Nose K, Saito H, Kuroki T. Isolation of a gene sequence induced later by tumor-promoting 12-O-tetradecanoylphorbol-13-acetate in mouse osteoblastic cells (MC3T3E1) and expressed constitutively in ras-transformed cells. Cell Growth Differ 1990;1:511-8.

20. Farr AG, Berry ML, Kim A, et al. Characterization and cloning of a novel glycoprotein expressed by stromal cells in T-dependent areas of peripheral lymphoid tissues. J Exp Med 1992;176:1477-82.

21. Wetterwald A, Hoffstetter W, Cecchini MG, et al. Characterization and cloning of the E11 antigen, a marker expressed by rat osteoblasts and osteocytes. Bone 1996;18: 25-132.

22. Rishi AK, Joyce-Brady M, Fisher J, et al. Cloning, characterization, and development expression of a rat lung alveolar type I cell gene in embryonic endodermal and neural derivatives. Dev Biol 1995;167:294-306.

23. Gonzalez RF, Dobbs LG. Purification and analysis of RT140, a type I alveolar epithelial cell apical membrane protein. Biochim Biophys Acta 1998;1429:208-16.

24. Breiteneder-Geleff S, Matsui, K, Soleiman A, et al. Podoplanin, novel 43-kd membrane protein of glomerular epithelial cells, is down-regulated in puromycin nephrosis. Am J Pathol 1997;151:1141-52.

25. Zimmer G, Klenk H-D, Herrler G. Identification of a 40kda cell surface sialoglycoprotein with the characteristics of a major influenza $C$ virus receptor in a MadinDarby canine kidney cell line. J Biol Chem 1995;270: 17815-22.

26. Zimmer G, Oefner F, von Messling V, et al. Cloning and characterization of gp36, a human mucin-type glycoprotein preferentially expressed in vascular endothelium. Biochem J 1999;341:277-84.

27. Ma T, Yang B, Matthay MA, et al. Evidence against a role of mouse, rat, and two cloned human T1 $\alpha$ isoforms as a water channel or a regulator of aquoporin-type water channels. Am J Respir Cell Mol Biol 1998;19: 143-9.

28. Kriehuber E, Breiteneder-Geleff S, Groeger M, et al. Isolation and characterization of dermal lymphatic and blood endothelial cells reveal stable and functionally specialized cell lineages. J Exp Med 2001;194: 797-808.

29. Williams MC, Cao YX, Hinds A, et al. T1 $\alpha$ protein is developmentally regulated and expressed by alveolar type I cells, chroid plexus, and ciliary epithelia of adult rats. Am J Respir Cell Mol Biol 1996;14:577-85.

30. Breiteneder-Geleff S, Soleiman A, Kowalski H, et al. Angiosarcomas express mixed endothelial phenotypes of blood and lymphatic capillaries. Podoplanin as a specific marker for lymphatic endothelium. Am J Pathol 1999;154:385-94.

31. Ramirez MI, Millien G, Hinds A, et al. T1 $\alpha$, a lung type I cell differentiation gene, is required for normal lung cell proliferation and alveolus formation at birth. Dev Biol 2003;256:61-72.

32. Schacht V, Ramírez MI, Hong Y-K, et al. T1 $\alpha /$ podoplanin deficiency disrupts normal lymphatic vasculature formation and causes lymphedema. EMBO J 2003;22:354656.

33. Wigle JT, Oliver G. Prox1 function is required for the development of the murine lymphatic system. Cell 1999;98:769-78.

34. Oliver G, Detmar M. The rediscovery of the lymphatic system. Old and new insights into the development and biological function of lymphatic vascular system. Genes Dev 2002;16:773-83.

35. Petrova TV, Mäkinen T, Mäkelä T, et al. Lymphatic endothelial reprogramming of vascular endothelial cells by the Prox-1 homeobox transcription factor. EMBO J 2002;17:4593-9.

36. Wigle JT, Harvey N, Detmar M, et al. An essential role for Prox1 in the induction of the lymphatic endothelial cell phenotype. ЕMBO J 2002;21:1505-13.

37. Hong Y-K, Harvey N, Noh Y-H, et al. Prox1 is a master control gene in the program specifying lymphatic endothelial fate. Dev Dyn 2002;225:351-7.

38. Swartz MA, Skobe M. Lymphatic function, lymphangiogenesis, and cancer metastasis. Microsc Res Techniq 2001;55: 92-9.

39. Karpanen T, Alitalo K. Lymphatic vessels as targets of tumor therapy? J Exp Med 2001;194: F37-42.

40. Stacker SA, Achen MG, Jussila L, et al. Lymphangiogenesis and cancer metastasis. Nature Rev Cancer $2002 ; 2$ : 573-83.

41. Pepper MS. Lymphangiogenesis and tumor metastasis: Mith or reality? Clin Cancer Res 2001;7: 462-8.

42. Sleeman JP, Krishnan J, Kirkin V, et al. Markers of the lymphatic endothelium: In search of the holy grail? Microse Res Techniq 2001;55: 61-9.

43. Birner P, Shindl M, Obermair A, et al. Lymphatic microvessel density in epithelial ovarian cancer: its impact on prognosis. Anticancer Res 2000;20:2981-5.

44. Muñoz-Guerra MF, Marazuela EG, Martín-Villar E, et al. Prognostic significance of intratumoral lymphangiogenesis in squamous cell carcinoma of the oral cavity: A study of the early stages [in press]. Cancer.

45. Aoki S, Shimamura T, Shibata T, et al. Prognostic significance of dysadherin expression in advanced colorectal carcinoma. Br J Cancer 2003;88:726-32.

46. Shimamura T, Sakamoto N, Ino Y, et al. Dysadherin overexpression in pancreatic ductal adenocarcinoma reflects tumor aggressiveness. Relationship to E-cadherin expression. J Clin Oncol 2003;21:659-67. 
47. Bissell MJ, Radisky D. Putting tumors in context. Nature Rev Cancer 2001;1:46-54.

48. Takahashi K, Sasaki T, Mammoto A, et al. Direct interaction of the Rho GDP dissociation inhibitor with ezrin/radixin/moesin initiates the activation of the Rho small G protein. J Biol Chem 1997;272:23371-5.

49. Berryman M, Franck Z, Bretscher A. Ezrin is concentrated in the apical microvilli of a wide variety of epithelial cells whereas moesin is found primarily in endothelial cells. J Cell Sci 1993;105:1025-43.

50. Amieva MR, Wigenbus KK, Furthmayr H. Radixin is a component of hepatocyte microvilli in situ. Exp Cell Res $1994 ; 210: 140-4$
51. Scholl FG, Gamallo C, Quintanilla M. Ectopic expression of PA2.26 antigen in epidermal keratinocytes leads to destabilization of adherens junctions and malignant progression. Lab Invest 2000;80:1749-59.

52. Angata T, Brinkman-Van der Linden ECM. I-type lectins. Biochim Biophys Acta 2002;1572:294-316.

53. Boucherot K, Schreiber R, Pavenstadt H, et al. Cloning and expression of the mouse glomerular podoplanin homologue gp38p. Nephrol Dial Transplant 2002;17:978-84.

54. Taniguchi K, Harada N, Ohizumi I, et al. Molecular cloning and characterization of antigens expressed on rat tumor vascular endothelial cells. Int J Cancer 2000;86: 799-805. 